\title{
Útiles sobre soportes naturales (tectoclastos) en el Auriñaciense: el ejemplo de Cueva Morin (Villanueva de Villaescusa, Cantabria)
}

\author{
JOSÉ MANUEL MAILLO FERNÁNDEZ ${ }^{1}$
}

\begin{abstract}
RESUMEN
RÉSUMÉ

En este trabajo se presentan una

Dans cet travail nous voulons serie de piezas retocadas sobre soportes naturales (tectoclastos) en el nivel 7 (auriñaciense) de Cueva Morin

(Cantabria). Se analiza el origen de estos soportes (morfologias generales y estigmas particulares). Estos soportes son empleados para realizar diferentes tipos de utensilios, destacando los raspadores de tipo auriñaciense? ${ }^{2}$.

PALABRAS CLAVE Útiles sobre soportes naturales, tectoclastos, tipologia, auriñaciense, Cueva Morin, Cantabria. présenter une série de pièces retouchées sur support naturels (tectofracts) à la couche 7 (aurignacien) de Cueva Morin (Cantabria, Espagne). Nous faisons l'analyse de ces supports (morphologie générale et stigmates particuliers). Ces supports sont employés pour faire différents types d'outils, sourtout les grattoirs de type aurignacienne.

MOTS CLEF

Outils sur supports naturels, tectofracts, typologie, aurignacien, Cueva Morin, Cantabria.

\footnotetext{
1 Becario F.P.U. del M.E.C. Dpto. de Prehistoria e Historia Antigua. U.N.E.D. e-mail: chon-

2 Este apartado está extraido del texto en preparación "Sur le tectu fracte de J. Pellegrín.
} chi36@hotmail.com. (CNRS UMR 7055, MAE, 21, allée de l'Université, 92023, Nanterre, Cedex), a quien agradecemos el interés y apoyo prestado.
\end{abstract}


Tradicionalmente, la naturaleza del soporte en la caracterización de los útiles retocados ha sido siempre una caracteristica menor, siendo la morfología el carácter más importante en su definición. Así se definen los diferentes tipos como "lasca $u$ hoja que presenta..." (Sonneville-Bordes \& Perrot, 1954). Ya en este encabezamiento, la panoplia auriñaciense se presenta como resultado del modo de talla más empleado en el paleolítico superior: el débitage, ya de lascas, ya de hojas.

Nosotros queremos presentar en este trabajo una serie de piezas retocadas que no han sido realizadas sobre soportes tallados por débitage en el nivel 7 (auriñaciense) de Cueva Morin. Se trata de piezas que, desde un punto de vista tipológico estricto, deberian estar realizadas sobre hojas o lascas y que están confeccionados sobre fragmentos fracturados geológicamente.

\section{EL YACIMIENTO}

Cueva Morín también denominada cueva del Rey o Mazo Moril, se encuentra en Villanueva de Villaescusa en la provincia de Santander, dentro de la cuenca de drenaje de la ría de Solía. Se encuadra geológicamente en una pequeña colina de calizas del complejo urgoniano (posiblemente aptense), a más de sesenta metros sobre el nivel del mar y a unos seis kilómetros de la actual línea de costa. La entrada se orienta al NW, siguiendo en dirección SE para terminar hacia el SW y presenta una altura en la boca de dos metros (González Echegaray \& Freeman, 1971).

Fue descubierta por Obermaier y Wermert en 1910. En $1912 \mathrm{~J}$. Carballo y $P$. Sierra realizan un pequeño sondeo que no publican. Publicación que si realiza $O$. Cendrero de unos materiales extraídos de la pequeña cuadrícula de Carballo (Cendrero, 1915). Entre 1917-1919 se llevan a cabo las primeras excavaciones sistemáticas en la cueva por parte de J. Carballo en una superficie de diez por dos metros, con una profundidad de dos metros. Se pusieron en evidencia los niveles del Paleolítico Superior y dos del Paleolítico Medio (Carballo, 1923). En 1918, J. Carballo invita al Conde de la Vega del Sella a excavar el yacimiento tras las campañas del primero. Éstas, que se prolongaron hasta 1920, fueron rápidamente dadas a conocer (Vega del Sella, 1921). La última intervención en el yacimiento fue la efectuada por González Echegaray y Freeman encabezando un equipo hispano-estadounidense en 1966, 1968 y 1969 (González Echegaray \& Freeman, 1971, 1973, 1978). Éstas aportaron a la prehistoria española dos aspectos hasta entonces inexistentes: una metodología apropiada (fue la primera excavación arqueológica realizada con métodos modernos) y, lo que resulta más importante, arrojó la primera secuencia completa del trán- 
Útiles sobre soportes naturales (tectoclastos) en el Auriñaciense: el ejemplo...

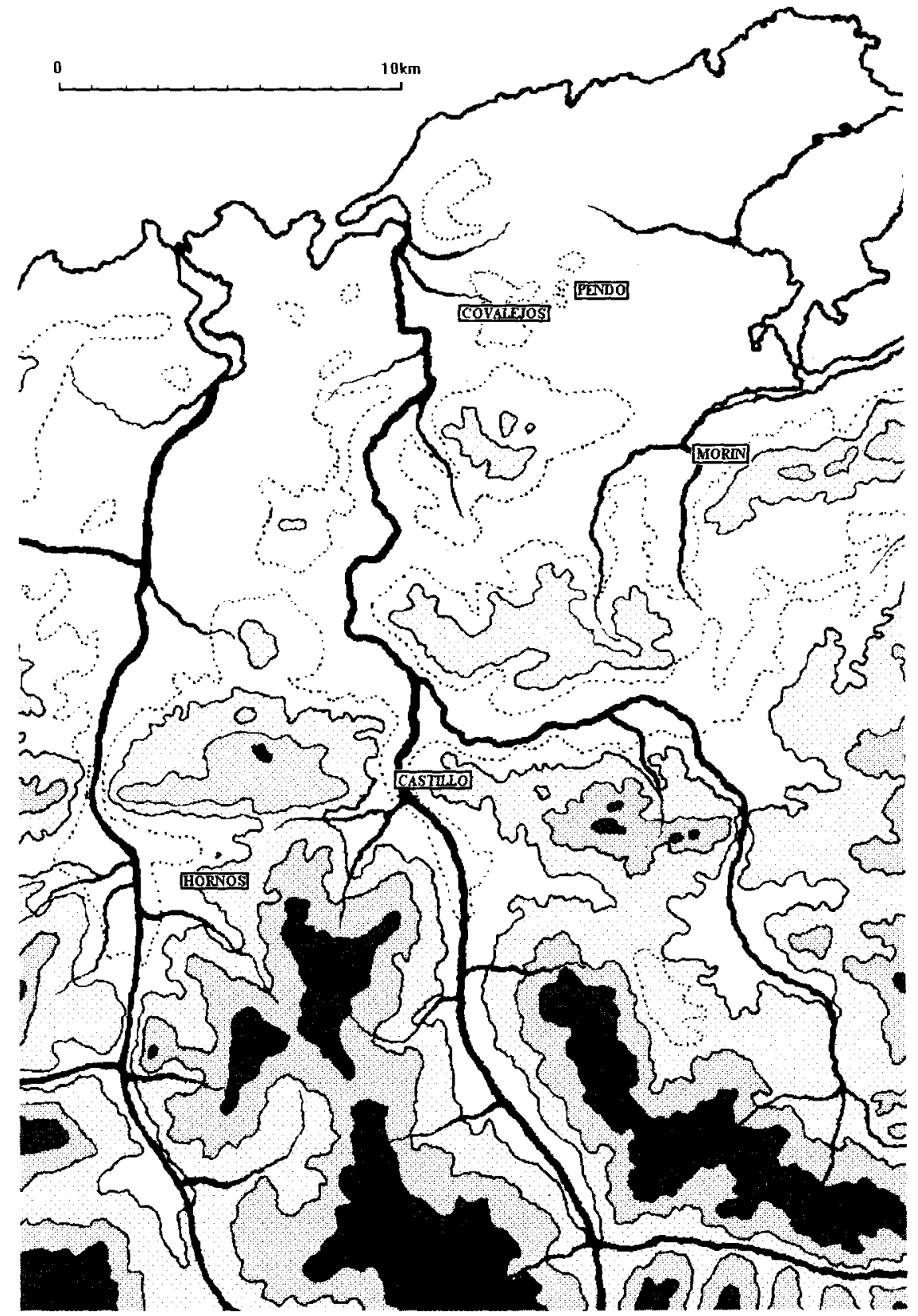

Figura 1. Cueva Morin en su contexto regional. 
sito entre el Paleolítico medio y el superior, terminando con el debate del auriñaco-musteriense.

La secuencia estratigráfica actual de la cueva se compone de un total de 22 niveles cuya atribución cultural es:

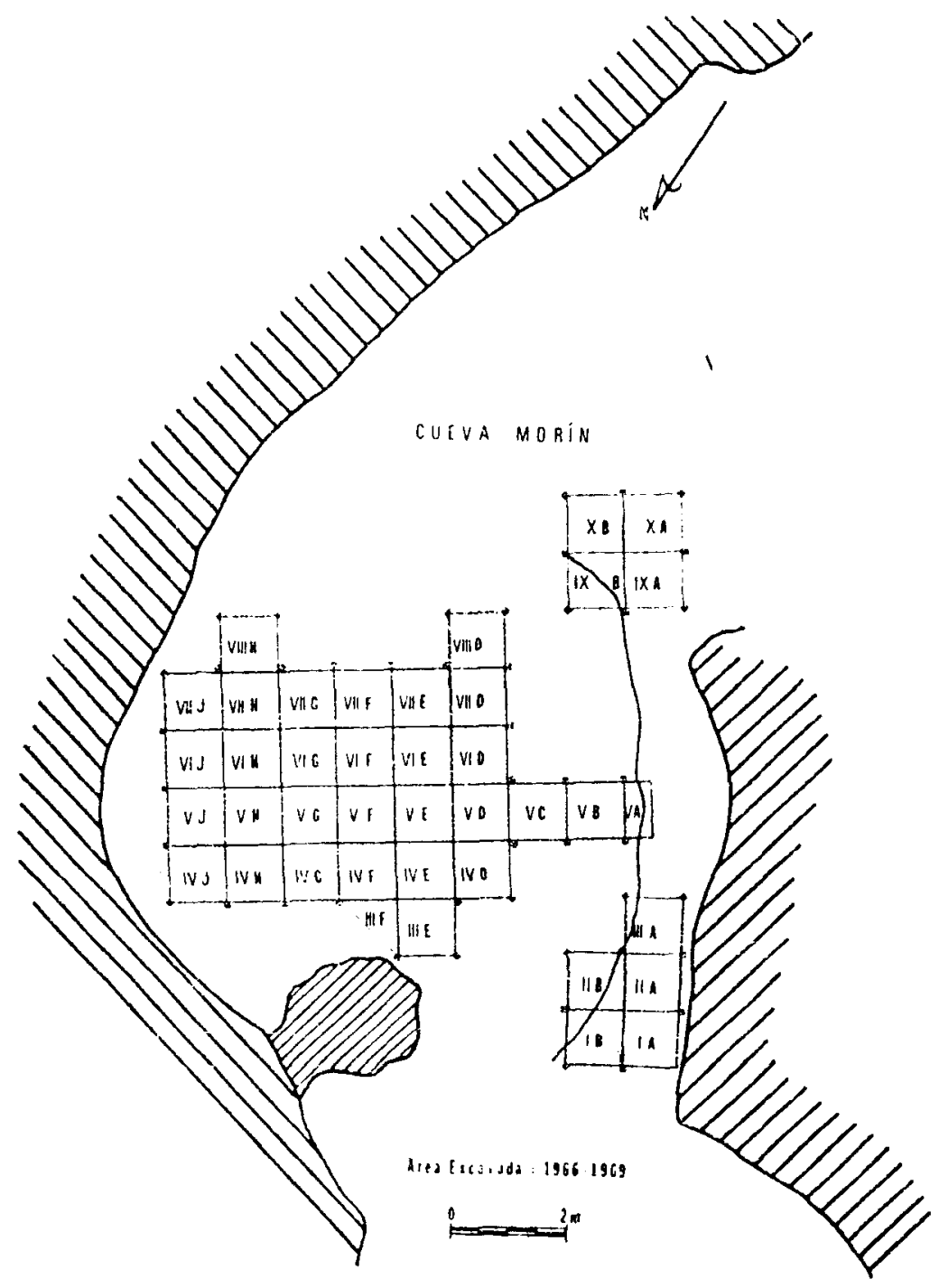

Figura 2. Planta de cueva Morin. 
Útiles sobre soportes naturales (tectoclastos) en el Auriñaciense: el ejemplo...

Nivel 1: aziliense.

Nivel 2: magdaleniense.

Nivel 3: solutrense superior.

Nivel 4: gravetiense.

Nivel 5: gravetiense y auriñaciense evolucionado.

Niveles 6 y 7: auriñaciense típico.

Niveles $8 a, 8 b$ y 9 : auriñaciense arcaico.

Nivel 10: chatelperroniense.

Niveles 11 a17: musteriense.

Niveles 18 al 22: estériles.

\section{EL NIVEL 7 DE CUEVA MORIN}

La caracterización tipológica del nivel es eminentemente auriñaciense ( $G A=19.4 ; G P=2.7$ ), según se desprende de las últimas revisiones de los materiales del yacimiento (Arrizabalaga, 1995; Bernáldo de Quirós, 1982; Echegaray \& Freeman, 1978). El número de raspadores supera ampliamente al de los buriles, siendo la mitad aproximadamente de tipo auriñaciense. Entre los buriles destacan los diedros. Posee un gran peso las raederas y los denticulados (35 y 14\% respectivamente). Las hojitas Dufour son escasas (en contraposición a lo que sucedía en los niveles subyacentes). Las hojas auriñacienses son discretas en número. La industria ósea es pobre: un fragmento de azagaya de sección circular y otra subcuadrangular, asi como un canino de ciervo perforado.

La fauna tampoco es demasiado representativa con dos ejemplares de bóvido, dos de corzo, uno de ciervo y otro de caballo. Las condiciones ambientales son difíciles de inferir debido a los problemas de conexión entre los datos sedimentológicos y polínicos, según apuntan algunos autores (Laville \& Hoyos, 1994), aunque podría corresponder a un clima frío en el que disminuye el bosque en favor de paisajes con plantas herbáceas (Leroi-Gourhan, 1971).

Por último disponemos de dos dataciones fiables de C14 para este nivel: $30.465 \pm 901$ y $27.565 \pm 865$ B.P. (Stuckenrath, 1978). 


\section{ANÁLISIS TECNO-TIPOLÓGICO}

Disponemos de un total de 38 piezas retocadas en silex que han sido confeccionadas sobre soportes brutos, más concretamente fracturadas de forma natural a causa de fenómenos tectónicos (tectoclastos). Estos fragmentos naturales de sílex, que presentan formas diversas, han sido empleados por los humanos de Morin para realizar una parte de sus utensilios.

\subsection{Aspectos generales ${ }^{3}$}

Describimos con el nombre de tectoclastos (tectofracts, término propuesto por P. Bintz del Instituto Geológico Dolomieu de Grenoble) a los nódulos de sílex que resultan de las fracturas naturales debidas a la deformación y la comprensión de su matriz calcárea en el curso de los movimientos tectónicos. Estos tectoclastos de sílex son también abundantes en las regiones montañosas con estratos calcáreos accidentados como lo Pirineos, los macizos pre-alpinos como la Chartreuse y le Vercors, la cordillera cantábrica, etc... Además, puede producirse en cualquier tipo de roca apta para la talla.

En el origen de este fenómeno, los movimientos de basculación y deslizamiento de los estratos se traducen en colosales fuerzas de compresión y cizalla que provocan una fracturación muy intensa de los nódulos en su matriz calcárea dura.

\section{- Morfología y estigmas de los tectoclastos}

Pueden presentar una morfología muy variable, aunque pueden reagruparse en tres categorias: tranches, bâtonnets y cubes ${ }^{4}$.

- Los tectoclastos en tranches (similares a «rodajas»), más o menos espesos y regulares, completos o fragmentados, son producto, sin duda, del efecto de cizalla del nódulo en su matriz dura. Sus caras son habitualmente planas, ni cóncavas, ni convexas.

- Los tectoclastos en bâtonnets, alargados y de sección poligonal son el resultado de una potente compresión bipolar opuesta: entre estos dos

\footnotetext{
3 Este apartado será ampliado y documentado con el pertinente aparato gráfico por J. Pelegrín en un trabajo posterior aún en elaboración.

4 Preferimos emplear la terminología en su idioma original.
} 
Útiles sobre soportes naturales (tectoclastos) en el Auriñaciense: el ejemplo...

polos, el nódulo es fallado en múltiples fisuras subparalelas, rectilíneas cerca del eje de compresión y más arqueadas en la periferia.

- Los tectoclastos en cubes se producen por la fragmentación secun daria, por una fuerza de cizalla, de un nódulo fracturado anteriormente el bâtonnets.

Dicho esto, según la forma inicial del nódulo y la intensidad de 1 . fuerza, la presión tectónica puede provocar esquirlas con las caras d fractura planas 0 arqueadas, muy similares a las los producidos por 1 percusión bipolar sur enclume. Estos son los estigmas que permiten $s$ distinción.

\section{- Estigmas particulares:}

Cuatro son los estigmas particulares, en ocasiones pueden aparec asociados en una misma cara de fractura, permitiendo un reconocimien claro del origen tectoclástico de dicha cara: las macro-lancettes, las "ma ques d'escalier", las fissures y rides particulières.

- Las macro-lancettes recuerdan las lancetas de la fractura concoid de origen antrópico, pero aquí son mucho más evidentes, pudiendo afect a la zona central de la cara de lascado estudiada. Su aspecto caricatural su extensión indican el enorme exceso de energía que antecedió a la fra tura tectóclástica, exceso que se traduce en una subdivisión reiterada c plano de fractura durante este proceso.

- Las "marches d'escalier", de hecho los décalages brutales, de á gulos marcados, de un plano principal de fractura, pueden derivarse $c$ mismo mecanismo, o señalar que el plano de fractura ha encontrado u fisura transversal preexistente.

- Las fissures internes visibles en la pieza son de igual forma u señal de fractura tectónica, aunque sin décalage en el plano de fractu en este caso, el plano de fractura observado se produce en primer lugar la fisura observable a contraluz se produce posteriormente.

- Por último, los rides particulières señalan el efecto de una presió no de un choque. En efecto, su examen con luz rasante revela su sur sión en línea quebrada, que refleja una progresión discontinua del fre de fractura, marcando las paradas y las reactivaciones de la fractura. $S$ la gelifración, siguiendo el mismo proceso, puede provocar estos mic rides angulosos. 
Sobre el terreno, los dos signos de fracturación tectónica que resultan más sencillos de reconocer son el aspecto plano de las caras de fractura (la fractura concoidal es convexa o cóncava), las macro-lancettes o las marques d'escalier ya que un simple frotado de la superficie con el dedo las pone en evidencia.

\subsection{Análisis empírico}

Disponemos de 38 tectoclastos retocados en el nivel 7 de Morín. Éstos están en su mayoría realizados en un tipo de sílex gris oscuro-negro, opaco y de grano fino. La fuente de esta materia prima actualmente es desconocida, aunque podría encontrarse en las cercanías del yacimiento o en la zona costera situada a pocos kilómetros al Norte del yacimiento (Sarabia, 1999a y b). Este tipo de piezas llamaron la atención a otros investigadores del yacimiento (Arrizabalaga, 1995: 420), siendo denominados como «trozos" de materia prima y a los que apenas se les dio ningún trato con relación al origen del soporte.

Como ya hemos comentado arriba, la morfología de estas piezas puede llegara ser muy variada. Nosotros distinguimos siete tipos de soportes de acuerdo con su morfología y que corresponden a variantes de los tres grupos generales ya comentados. Los tipos 1,2 y 7 corresponden a las bâtonnets, los 3 y 6 a las tranches y los 4 y 5 a los cubes. Su descripción somera es:

- Tipo 1: bâtonnets de sección triangular.

- Tipo 2: bâtonnets típica con cortex natural.

- Tipo 3: tranches alargada y rectangular, de grosor y tamaño variable.

- Tipo 4: tranches de morfología circular.

- Tipo 5: cubes.

- Tipo 6: cubes con un lado cortical y curvado.

- Tipo 7: bâtonnets de sección poliédricas.

El esquema técnico de producción empleado para la elaboración de estas piezas es bien sencillo. En primer lugar se elige el tectoclasto en relación morfológica con el útil que se quiere confeccionar. El siguiente paso es el retoque, que es realizado de una manera concisa y con el menor número de levantamientos posible. Así los tipos que encontramos son en su mayoría clasificados como «simples». 
Las piezas transformadas que encontramos en la colección del nivel 7 de Morín son en su mayoría raspadores y buriles. Además existen otros tipos como piezas con retoque sobre un lado, raederas, perforadores, muescas, etc (ver cuadro 1). Cuantitativamente los tipos 3, 2 y 4 son los más empleados. Si revisamos los tipos por grupos son los de tipo en tranches $(3$ y 6 ) los más empleados $(n=16)$. Seguidos de los bâtonnets $(n=10)$ y los cubes $(n=7)$, por último existen cinco piezas indeterminadas.

\begin{tabular}{lrrrrrrrrrrr}
\hline TIPO & T.1 & T.2 & T.3 & T.4 & T.5 & T.6 & T.7 & T.I & Total & lascal & Total \\
\hline 1. Raspador simple. & 1 & & 2 & & & 1 & & & 4 & 10 & 14 \\
2. Raspador atipico. & & & 1 & & & & & 2 & 3 & 7 & 10 \\
11. Raspador carenado. & & & 2 & 1 & & & & & 3 & 3 & 6 \\
12. Raspador carenado atipico. & 1 & & 1 & 3 & 1 & & & 2 & 8 & 13 & 21 \\
13. Raspador espeso en hocico. & 1 & & & & & & 1 & 7 & 8 \\
14. Raspador plano en hocico. & & 2 & 1 & & & & & 3 & 5 & 8 \\
23. Perforador. & 1 & & & & & 1 & 1 & 2 \\
27. Buril diedro recto. & & & 1 & & & & & 1 & 2 & 3 \\
30. Buril diedro sobre fractura. & 1 & & 1 & & & & & & 2 & 4 & 6 \\
47. Punta de Chatelperrón atip. & 1 & & & & & & 1 & & 1 \\
65. Pieza ret. sobre un lado. & 2 & & & & & 1 & & 3 & 25 & 28 \\
74. Muesca. & 2 & & & & & & & 2 & 13 & 15 \\
75. denticulado. & 1 & & & & & & 1 & 5 & 6 \\
77. raedera. & & 1 & 1 & & 1 & & 3 & 25 & 28 \\
92. diverso. & 3 & 6 & 14 & 6 & 1 & 2 & 1 & 5 & 38 & 127 & 165 \\
\hline Total & & & & & & & & 1 & 2 & 7 & 9 \\
\hline
\end{tabular}

Cuadro 1

Las piezas sobre tranches se emplean en casi todas las categorías tipológicas representadas. La mayoría son empleados en raspadores $(n=$ 9 ) y buriles $(n=2)$, (figura $3: 1-4,6$ y 7 ; figura $4: 1,3$ y 6 ). Aunque encontramos otras tipologias (figura 4: 5 y 6 ).

El tipo 4, dentro del grupo de las formas cúbicas, es más representativo que el tipo 5 ( 6 frente a 1 ejemplar) que casi exclusivamente se emplean para raspadores de tipo auriñaciense (figura $3: 5$ y 8).

El último grupo empleado, los bâtonnets (tipos 1, 2 y 7), está representado con 10 piezas. Observando este grupo, comprobamos como existe una dicotomía entre el tipo 1 exclusivo para raspadores y buriles (figura 4:2) y los tipos 2 y 7 para piezas con retoque sobre un borde, raederas, denticulados y piezas de dorso como una punta de Chatelperrón atípica (figura 3: 10-13; figura 4:4). 

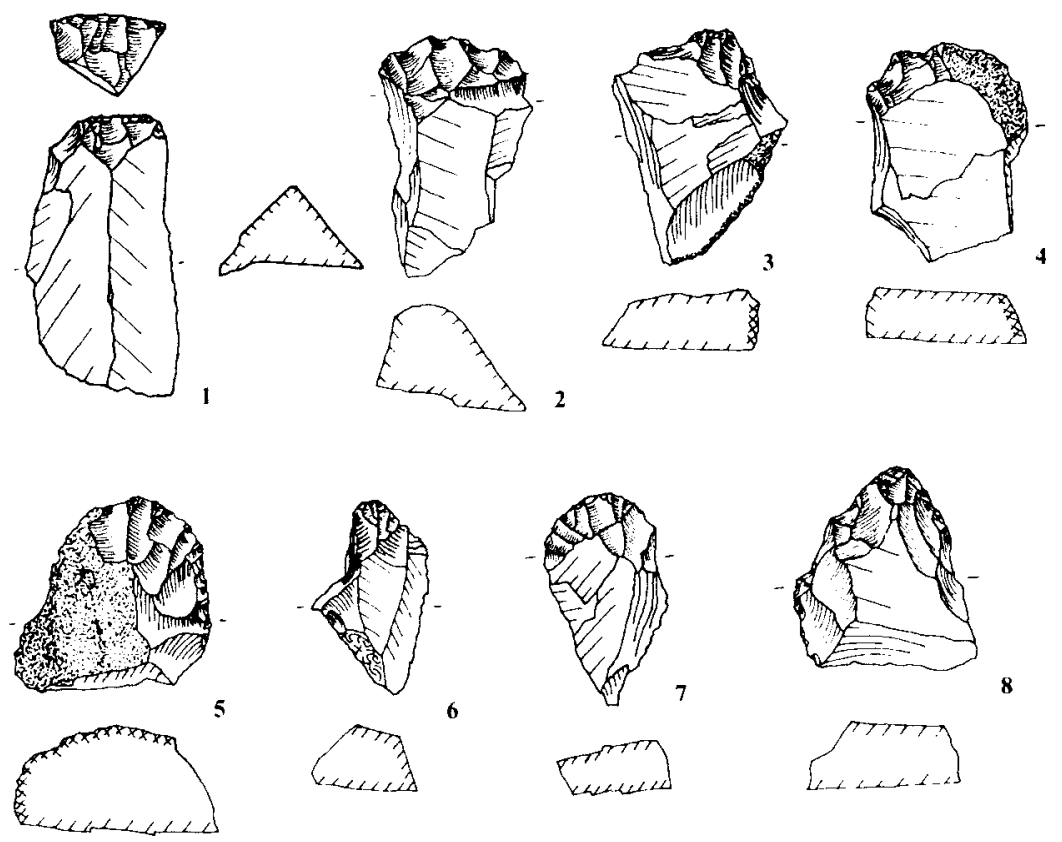

8

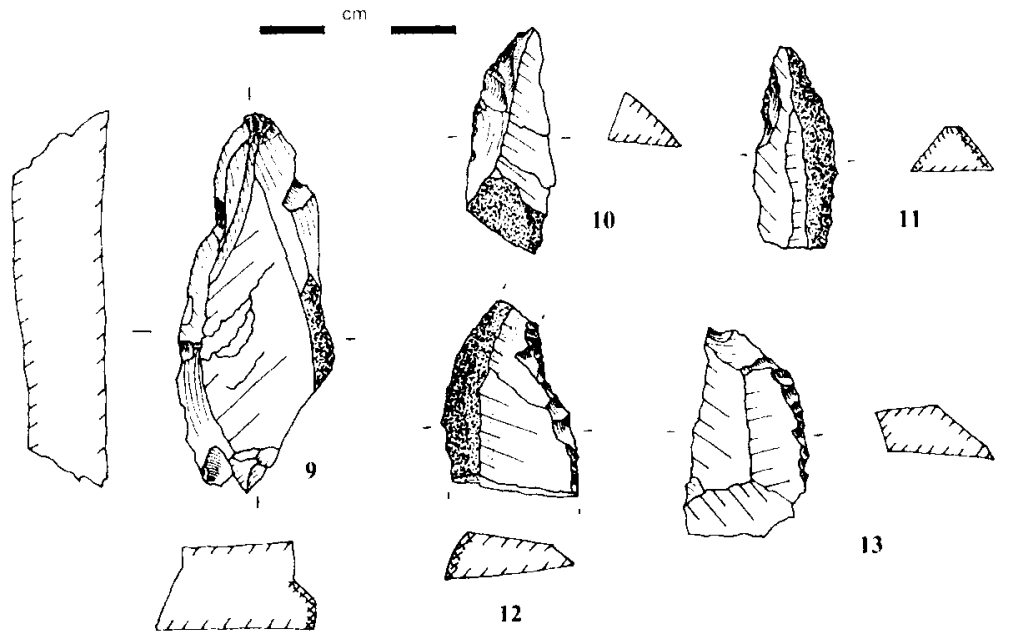

Figura 3. Piezas sobre tectoclastos: 1-9: raspadores; 10: punta de Chatelperrón atípica; 11-12: muescas; 13: pieza con retoque sobre un lado. 

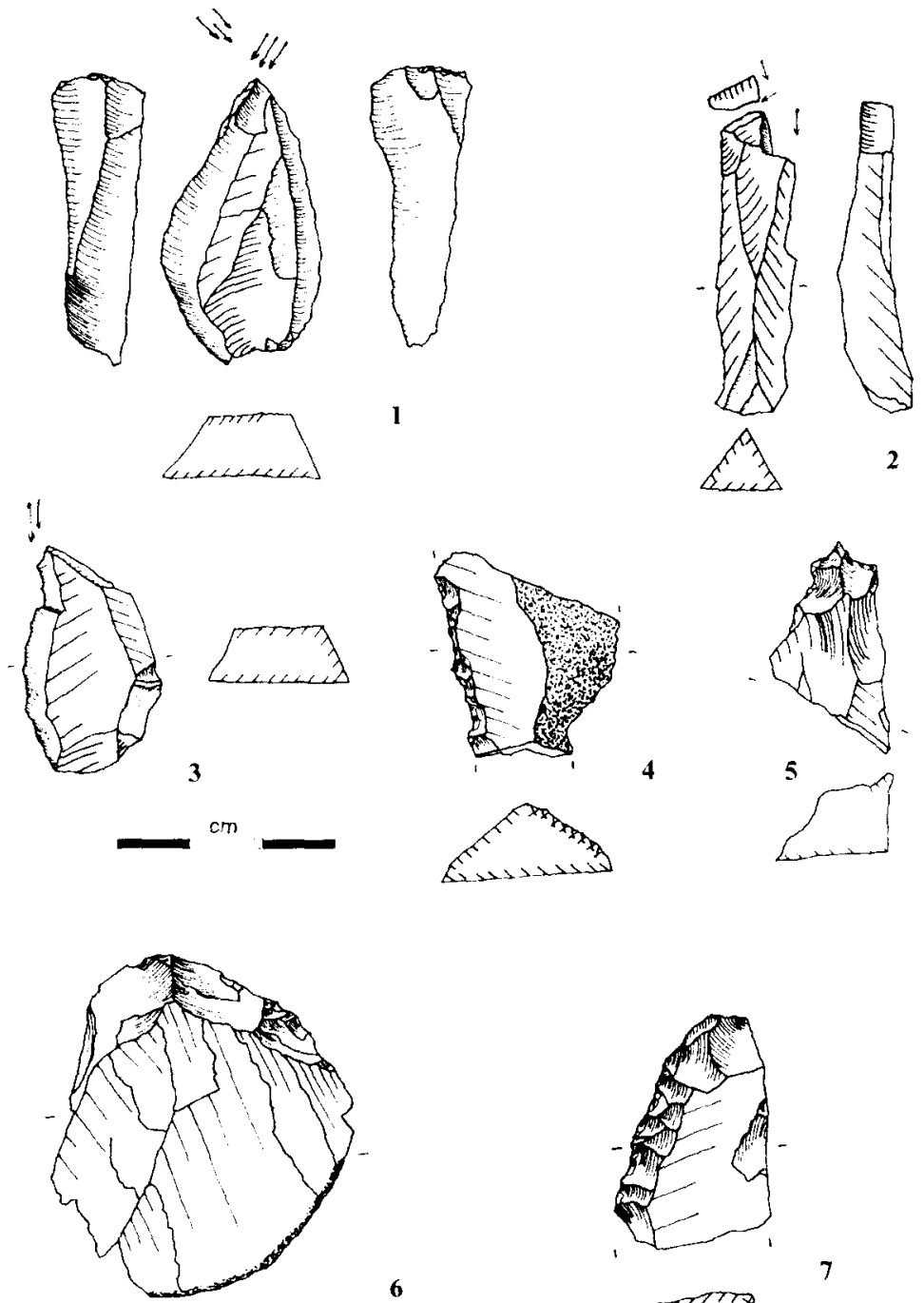

6

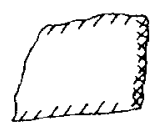

Figura 4. Piezas sobre tectoclastos: 1-3: buriles; 4: pieza con retoque; 5: perforador; 6-7: raederas. 
El problema se complica al encontrar en el yacimiento no sólo el material retocado sobre tectoclastos, sino también numerosas piezas de este tipo que no presentan estigmas de utilización (cuadro 2). Son en total 765 piezas las que poseen estigmas de fractura tectónica de manera clara, aunque el número podría duplicarse al existir numerosos fragmentos que, debido a su pequeño tamaño, no pueden incluirse en esta categoría con todas las garantías.

\begin{tabular}{rrrr}
\hline TIPO & sin retoque & retocado & TOTAL \\
\hline Tipo 1 & $20(87 \%)$ & $3(13 \%)$ & 23 \\
Tipo 2 & $29(82.9 \%)$ & $6(17.1 \%)$ & 35 \\
Tipo 3 & $232(94.3 \%)$ & $14(5.7 \%)$ & 246 \\
Tipo 4 & $29(82.9 \%)$ & $6(17.1 \%)$ & 35 \\
Tipo 5 & $12(92.3 \%)$ & $1(7.6 \%)$ & 13 \\
Tipo 6 & $124(98.5 \%)$ & $2(1.5 \%)$ & 126 \\
Tipo 7 & $114(99.1 \%)$ & $1(0.9 \%)$ & 115 \\
Tipo 1 & $205(97.6 \%)$ & $5(2.3 \%)$ & 210 \\
\hline TOTAL & $765(95.3 \%)$ & $38(4.7 \%)$ & 803 \\
\hline
\end{tabular}

Cuadro 2

Por tanto, tres cuestiones básicas cabrian hacerse:

¿Por qué se transportan estos fragmentos si no van a ser empleados? ¿Por qué se prefieren ciertos tipos de fragmentos a otros?

¿Qué ventajas presentan los tectofractos sobre el material de débitage?

Las respuestas no son fáciles. En cuanto a la primera pregunta, los tectofractos pueden ser transportados masivamente porque la fuente de materia prima puede estar muy próxima a la cueva, incluso en el propio monte del yacimiento (Sarabia, 1999a y b). Estos pueden transportarse en gran número para realizar actividades de talla, ya que la mayoría del débitage se realiza sobre los tectoclastos más apropiados (por tamaño o morfología). Si la fuente está próxima al yacimiento se puede explicar la aparición tan amplia de tectoclastos en el mismo.

La preferencia de unos tectoclastos sobre otros viene dada porque su morfología es la más adecuada para el retoque de útiles al presentar pocas irregularidades en las superficies. Esto viene corroborado por el estudio métrico entre los tectoclastos retocados y los que no lo están, ya que no se aprecia una selección métrica de los soportes. Ya hemos comentado como se produce una elección del soporte en relación con el "útil" que se quiere realizar, así, por ejemplo, se seleccionan cubes para los raspadores de tipo auriñaciense (carenados). También se emplean tec- 
toclastos para su explotación como núcleos de hojitas aprovechando su morfología y sin realizar apenas la fase de mise en forme.

Para la última cuestión tan sólo podemos decir que tanto métricamente como por retoque realizado no existen diferencias acusadas entre los tectoclastos retocados y el débitage como para hacernos pensar en una utilización específica de estos soportes por este motivo. Además, la diversidad de piezas retocadas realizadas sobre tectoclastos tampoco hacen pensar en esta posibilidad. Por lo que debemos planteamos una utilización oportunista del tectoclasto (adecuación morfo-métrica) para la confección de útiles retocados, sobre todo en raspadores de tipo auriñaciense.

\section{DISCUSIÓN}

Tras el estudio del material retocado sobre piezas de fractura natural encontramos los siguientes puntos de discusión:

1. La excepcionalidad de este tipo de soportes en colecciones paleolíticas, al menos hasta la fecha, unido a la dificultad de reconocimiento de sus características diagnósticas provoca que muchos de éstos conjuntos sean asimilados a los comúnmente empleados (lascas, hojas). Esto ha ocurrido en anteriores estudios del material de Morin (González Echegaray \& Freeman, 1971, 1973, Arrizabalaga, 1995).

2. Desde un punto de vista económico, el soporte se adapta totalmente al útil que se desea realizar. Así, los tectoclastos son elegidos por sus cualidades morfo-métricas (acordes al resto del material retocado). Las modalidades de transformación de estos soportes son muy simples al no necesitar ningún tipo de preparación previa (bien para la extracción de hojitas o para el retoque).

3. El protagonismo de este tipo de piezas en el conjunto del material retocado es dispar. Entre los raspadores, sobre todo los carenados, su papel es relevante (siendo en algunos casos el 50\% de las piezas). Esto también lo encontramos en el grupo de los buriles ya que donde están representados presentan el mismo porcentaje. Sin embargo, en piezas de sustrato como las raederas, denticulados, muescas, piezas con retoque en un borde, etc, apenas tienen importancia.

4. Pensamos que estos tipos de útiles han de ser asimilados al común y no recibir un trato singular desde un punto de vista exclusivamente tipológico. Creemos esto por las características intrínsecas que presentan las tipologías, al tratarse únicamente de una herramienta para la interpretación 
de los conjuntos arqueológicos. Sin entrar aquí en debates sobre la certeza de ciertas piezas como útiles o núcleos, por ejemplo, ya que de todos modos eran empleados por los grupos auriñacienses.

Es, desde un punto de vista tecnológico, donde debe ser tenida en consideración la naturaleza de estos soportes, ya que no sólo implican formas de talla poco comunes como el retoque directo sobre soporte natural, sino que para la región cantábrica resultan una herramienta muy importante para conocer la relación y el uso que los grupos humanos auriñacienses hacian de su territorio. Así como para solucionar los problemas de accesibilidad a las materias primas silíceas en este contexto geográfico.

\section{AGRADECIMIENTOS}

El autor desea dar las gracias a los componentes del projet collectif de recherche: "comportements techniques et économiques des sociétés au paléolithique supérieur dans le contexte pyrénéen" dirigido por N. Cazals por sus comentarios y propuestas para llevar a buen puerto este trabajo. Al personal del Museo Regional de Prehistoria y Arqueologia de Cantabria por las facilidades para realizar el mismo.

\section{BIBLIOGRAFIA}

Arrizabalaga, A. (1995): La industria lítica del Paleolitico Superior Inicial en el oriente cantábrico. Tesis doctoral, Univ. del País Vasco, p. 1025.

Bernaldo de QuiRós, F. (1982): Los inicios del Paleolítico Superior cantábrico. Monografías del centro de investigación y museo de Altamira, 8.

Carballo, J. (1923): Excavaciones en la Cueva del Rey, en Villanueva (Santander). Junta Superior de Excavaciones y Antigüedades, 9. p. 40, IX lám.

Cendrero, O. (1915): Resumen de los bastones perforados de la Provincia de Santander. Noticia de dos nuevos yacimientos prehistóricos de la Provincia de Santander. Com. de Invest. Paleontolog. y Prehit. Notas 1 y 2 . Madrid.

Gonzalez Echegaray, J. \& Freeman, L.G. (1971): Cueva Morín. Publicaciones del Patronato de las cuevas prehistóricas de la provincia de Santander, VI. p. 452.

- L.G. (1973): Cueva Morin. Publicaciones del Patronato de las cuevas prehistóricas de la provincia de Santander, X. p. 304.

- (1978): Vida y muerte en cueva Morin. Instituto cultural de Cantabria, colección de bolsillo, 7. p. 357

LAVILLE, H. \& Horos, M. (1994): Algunas precisiones sobre la estratigrafía y sedimentología de la cueva Morin (Santander). En Bernáldo de Quirós, F. (ed.): El cuadro geocronológico del Paleolítico Superior Inicial. Museo y Centro de investigación de Altamira. Monografías, 13: 200-209.

Lerol Gourhan, Arl. (1971): Análisis polínico de Cueva Morin. En González Echegaray, J. \& Freeman, L.G.: Cueva Morín. Publicaciones del Patronato de las cuevas prehistóricas de la provincia de Santander, VI: 357-365.

Sarabia Rogina, P. M. (1999a): Aprovechamiento y utilización de materias primas liticas en los tecnocomplejos del Paleolítico en Cantabria. Tesis doctoral. Univ. de Cantabria. p. 842. 
Útiles sobre soportes naturales (tectoclastos) en el Auriñaciense: el ejemplo...

- (1999b): Notas sobre los modelos de aprovisionamiento de materias primas líticas en el Paleolítico Superior de cueva Morin (Villanueva de Villaescusa, Cantabria). En: Homenaje al Dr. García Guinea. Sautuola, VI: 145-154.

Sonneville-Bordes, D. \& PerRot, J. (1954): Lexique typologique du Paléolithique supérieur. B.S.P.F., 51: 327-335; 52: 76-79; 53: 408-412; 547-559.

StuckenRath, R. (1978): Dataciones de C-14. En González Echegaray, J. \& Freeman, L.G. (ed.): Vida y muerte en cueva Morin. Instituto cultural de Cantabria, colección de bolsillo, 7: 215.

VEGA DEL SELLA, CONDE DE LA (1921): El Paleolítico de Cueva Morín (Santander y Notas para la climatología Cuaternaria. Comisión de Investigaciones Paleontológicas y Prehistóricas, Memoria 29. p. 168. 